\title{
EXTENSÃO UNIVERSITÁRIA E A FORMAÇÃO DOCENTE: ATUAÇÃO DO CURSO DE LICENCIATURA EM GEOGRAFIA DA UNIMONTES NO PROGRAMA BIOTEMAS (2018)
}

\author{
UNIVERSITY EXTENSION AND TEACHERS 'TRAINING: \\ PERFORMANCE OF THE LICENSE COURSE IN GEOGRAPHY \\ UNIMONTES IN THE BIOTEMAS PROGRAM (2018)
}

\author{
Carolina Cabral das Chagas Reis ${ }^{1}$ \\ Rahyan de Carvalho Alves ${ }^{2}$ \\ Dulce Pereira dos Santos ${ }^{3}$
}

\section{RESUMO}

O Programa Biotemas tem como objetivo integrar a comunidade acadêmica da Universidade Estadual de Montes Claros - Unimontes - e a educação básica, operacionalizando a partir da compreensão do tripé ensino, pesquisa e extensão, isto é, proporcionar aos acadêmicos dos diversos cursos a integração entre a Comunidade, no caso desse programa a educação básica, e a Universidade, possibilitando a realização e produção do conhecimento, no processo ensinoaprendizagem. Nesse contexto, o objetivo deste trabalho é compreender a atuação do curso de Geografia - Licenciatura no Fórum Biotemas, no ano de 2018, ressaltando o ensino dessa na educação básica. Para tanto, utilizaram-se como metodologia o levantamento e análises dos dados do Programa Biotemas no ano de 2018, verificando os temas abordados nas oficinas realizadas pelos acadêmicos do supracitado curso, em uma pesquisa estado da arte. A pesquisa aponta a aplicação de temas voltados, especialmente, à Geografia Física, a saber: Cartografia, Geoprocessamento, Geologia e Biomas. Ademais, vale destacar que o Biotemas se apresenta como estratégico e relevante para a formação do futuro professor, dado que proporciona o contato do acadêmico com o universo escolar, preparando-o para o mundo de trabalho e seus meandros socioeducacionais, políticos, econômicos, culturais dentre outros.

Palavras-chave: Biotemas. Extensão. Ensino Formação Docente. Universidade.

\section{ABSTRACT}

The Biotemas Program aims to integrate the academic community of the State University of Montes Claros - Unimontes - and basic education, operating from

\footnotetext{
${ }^{1}$ Graduada em Geografia pela Universidade Estadual de Montes Claros (UNIMONTES). E-mail: carolinacabral36@gmail.com. Lattes: http://lattes.cnpq.br/3369662927697438. ORCID: 00027175-6898

2 Professor Mestre do curso de Geografia da UNIMONTES. E-mail: rahyan.alves@ unimontes.br. Lattes: http://lattes.cnpq.br/0593456424985792. ORCID: 0001-7225-5959.

3 Professora Doutora do curso de Geografia da UNIMONTES. E-mail: dulcipsantos@yahoo.com.br. Lattes: http://lattes.cnpq.br/1213687288745503. ORCID:00034809-2824.
}

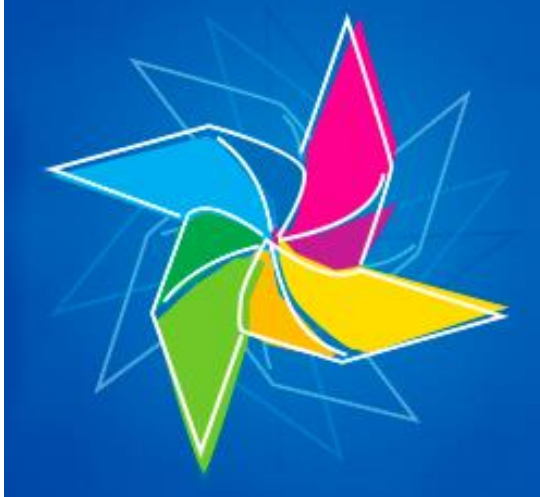


the understanding of the teaching, research and extension tripod, that is, to provide integration to the students of the various courses between the Community, in the case of this program, basic education, and the University, enabling the realization and production of knowledge, in the teaching-learning process. In this context, the objective of this work is to understand the performance of the Geography Graduation course at the Biotemas Forum, in 2018, with an emphasis on teaching this in basic education. To this end, the methodology used was the survey and analysis of data from the 2018 Biotemas Program, verifying the topics covered in the workshops held by the students of that course. The research points to the application of themes focused especially on Physical Geography, namely: Cartography, Geoprocessing, Geology, and Biomes. Also, it is worth noting that Biotemas presents itself as strategic and relevant for the formation of the future teacher, since it provides the academic's contact with the school universe, preparing him for the job market and its socio-educational, political, economic aspects, cultural complexities, among others.

Keywords: Biotemas. Extension. Teaching Teacher Training. University.

\section{INTRODUÇÃO}

No ano de 2004, por meio das atividades realizadas pelo Departamento de Estágios e Práticas Escolares (DEPE), especialmente por meio da disciplina Estágio Curricular Supervisionado do curso de Licenciatura em Biologia da Universidade Estadual de Montes Claros (Unimontes), surgiu o Programa Biotemas, coordenado pela professora Luzimara Silveira Braz Machado.

O projeto Biotemas tem como objetivo integrar a comunidade acadêmica da Universidade Estadual de Montes Claros à educação básica e compreender o tripé ensino, pesquisa e extensão, isto é, por meio do Biotemas, a Unimontes proporciona aos acadêmicos dos diversos cursos (licenciaturas e bacharelados) a integração entre a educação básica e a universidade, possibilitando, assim, a realização e produção do conhecimento, no processo de ensino-aprendizagem, encurtando as distâncias (físicas e dos produtos práticos) dos saberes produzidos no meio científico com a população.

O objetivo geral do Programa Biotemas é integrar a sociedade em geral à comunidade acadêmica na busca de socializar a produção científica, tecnológica e cultural das diversas áreas do conhecimento, e oferecer, em especial, serviços e produtos para as Escolas Públicas; além de incentivar a formação científica do acadêmico do ensino superior e da educação básica por meio, por exemplo, de atividades de iniciação científica, oficinas, stands, minicursos, feiras de ciências, elaboração de projetos que promovam o desenvolvimento social da região (BIOTEMAS, 2020).

Nos últimos anos, o Biotemas tem atuado na produção do conhecimento e a novas formas de ensinar e aprender. Auxiliando nas reformulações de concepções e práticas (extra)curriculares da universidade, bem como para a sistematização inovadora do conhecimento produzido e formas/técnicas de aplicação dessas medidas, em benefício da comunidade - interna e externa - capacitando acadêmicos para o planejamento, execução e liderança em minicursos, oficinas, palestras e apresentações de trabalhos científicos, visitas 
técnicas, exposições, concursos literários, shows artísticos, congressos, encontros, simpósios e mesas redondas no contexto da formação profissional (BIOTEMAS, 2020).

Segundo o Plano Nacional de Extensão (2010, p. 12), “A Extensão Universitária é o processo educativo, cultural e científico que articula o Ensino e a Pesquisa de forma indissociável e viabiliza a relação transformadora entre universidade e sociedade". Nesse sentido, a extensão possibilita o desenvolvimento profissional e cidadão do acadêmico como de quem recebe os seus serviços, tornando uma atividade, cada vez mais, junto à sociedade, e conseguindo emergir no imaginário social que a universidade não é um território fragmentado de produção do conhecimento.

Nesse contexto, o objetivo deste trabalho é compreender a atuação do curso de Geografia - Licenciatura no Fórum BIOTEMAS no ano de 2018, ressaltando o ensino de Geografia na educação básica. De forma mais objetiva, pretende-se levantar os dados do Biotemas no ano de 2018, analisar a importância do Biotemas para o curso de Geografia através dos temas abordados nas oficinas realizadas nesta edição do fórum. Para tanto, utilizaram-se como metodologia o levantamento e análises dos dados do Programa Biotemas no ano de 2018, verificando os temas abordados nas oficinas realizadas pelos acadêmicos do supracitado curso, em uma pesquisa estado da arte. Além disso, é importante destacar que o trabalho possui a natureza qualitativa e descritiva.

\section{A importância da indissociação da Pesquisa, Ensino e Extensão na formação do Professor}

A compreensão sobre a indissociabilidade entre ensino, pesquisa e extensão, não limita apenas a uma discussão legislativa ou conceitual, mas, essencialmente, paradigmática, epistemológica e pedagógica, uma vez que está associada às funções e à razão de ser uma universidade. A ligação intrínseca entre ensino, pesquisa e extensão define-se, de acordo com Rays (2003, p. 73), como “[...] um processo multifacetado de relações e de correlações que busca a unidade da teoria e da prática com base no bem do povo", pois se firma com o princípio das atividades fins das universidades, considerando-se que esse tripé firma a base fundamental do saber científico e não pode ser compartimentado.

A pesquisa está profundamente ligada ao ensino, ela é um processo sistemático que tem por objetivo a estruturação de um novo saber científico e compreende todas as áreas do conhecimento: literário, pedagógico, saúde, arquitetônico, em suma, o objetivo deve estar pautado em descobrir algo novo ou melhorar o que está posto, todavia, com bases comprovadas, por meio de uma atividade metodológica confiável (MOITA; ANDRADE, 2002). 
Já a extensão propicia um vínculo entre universidade e sociedade, concedendo à comunidade parte do aprendizado obtido no ensino superior, com o propósito de melhorar as questões sociais. Segundo o Plano Nacional de Extensão, “A Extensão Universitária é o processo educativo, cultural e científico que articula o Ensino e a Pesquisa de forma inseparável e viabiliza a relação transformadora entre universidade e sociedade [...]" (BRASIL, 2007, p. 11).

Nesse sentido, os futuros docentes precisam contribuir com a formação social a partir do que foi aprendido na graduação, sendo importante salientar que as ações de extensão reforçam para tal, uma vez que, nos espaços escolares e não escolares, a educação tem um papel importante na disseminação de conhecimentos, colaborando com o entendimento acerca da cidadania, direitos, além de conhecê-los e fazê-los valer (VIDAL; ALVES, 2020).

As ações de extensões proporcionam aos futuros profissionais da educação, ampliar as práticas teórico-metodológicas, enriquecendo seus conhecimentos, reconhecendo-se e identificando com o locus de trabalho, além de contribuir para a formação como futuros professores (RAYS, 2003).

De acordo com Freire (1983), para a transformação sociopolítica, os acadêmicos não podem ser objetos da ação dos realizadores dos projetos de extensão apenas por participar, pois as pessoas são agentes de transformação como os executores do projeto. Os acadêmicos devem sentir-se motivados a entender que a sociedade necessita dos seus serviços, especialmente no campo da educação.

Para Altet (2001), o docente é um profissional do ensino e da aprendizagem, formado para conquistar as competências necessárias ao ato de ensinar, o saber ensinar, e não apenas para dominar conteúdos de ensino, os conhecimentos disciplinares. Assim, as competências que tornam o docente um profissional, com destaque, são de disposição cognitiva, afetiva e prática. São também de disposição técnica e didática na preparação dos conteúdos e de ordem relacional, pedagógica e social na adaptação às interações em sala de aula.

O professor é um profissional do ensino, pois detém o conhecimento sobre o que e de que maneira ensinar a alguém. Seu trabalho é múltiplo, consiste na sistematização de saberes que dizem respeito à cultura erudita e, também popular, vinculados à ciência, à arte, à filosofia. É um trabalho realizado de modo intencional mediante a apropriação de um conhecimento específico que requer formação especializada. É uma tarefa complexa que envolve domínio rigoroso dos campos técnico e didático, além de constante postura de questionamento sobre sua ação (SANTOS, 2010).

A extensão universitária vinculada ao ensino e à pesquisa pode ser grande contribuinte na formação dos estudantes de modo geral e na constituição da identidade profissional do 
licenciando, pois agrega saberes e práticas que são fundamentais para o educador. Sendo assim, a participação dos graduandos em projetos de extensão, durante a formação do acadêmico, é tomada como fundamental no processo educativo implementado na universidade, uma vez que contribuirá para sua compreensão como ser socialmente responsável e livre, capaz de refletir sobre o vivido e o aprendido em sala de aula e outros espaços, como na comunidade, que vão construindo cotidianamente sua identidade pessoal e profissional, alicerçada na busca do saber ser, saber fazer e saber aprender, ou seja, na formação de suas competências (CAVALCANTE, 2000).

É nesse contexto que o projeto de extensão promove a inserção do acadêmico no seu ambiente de trabalho e o conduz para a sua futura carreira de docência, sendo esse um campo rico para a construção e reconstrução de conhecimentos.

Nessa perspectiva, o objetivo da Educação Geográfica não é somente transmitir os conhecimentos produzidos pela universidade, mas também construir, produzir e fortalecer o ensino de Geografia. A abertura das universidades para a extensão universitária conduz os discentes a um universo mais dinâmico, uma vez que a realização das atividades da extensão é geralmente direcionada para público não acadêmico. Consequentemente, a extensão torna-se um meio de democratização do conhecimento para grande parte da sociedade que ainda não teve acesso ao conhecimento científico.

\section{Alguns Programas de Extensão na UNIMONTES}

A Universidade Estadual de Montes Claros proporciona a extensão universitária por meio de diversos programas e projetos realizados em parceria com outras intuições de ensino superior, professores, acadêmicos e escolas de ensino básico. Entre eles vale ressaltar: o Programa Biotemas, Programa de Educação Tutorial (PET), Programa Institucional de Bolsa de Iniciação à Docência (PIBID), Programa Residência Pedagógica (RP), Projeto Núcleo de Atividades para Promoção da Cidadania (NAP) e Projeto Unimontes Solidária.

Os projetos de extensão realizados na Universidade Estadual de Montes Claros possibilitam aos graduandos, especialmente os de licenciatura, o vínculo entre teoria e prática, além de oportunizar uma relação com a sociedade, o ensino superior e a educação básica. Ou seja, ao participar desses projetos são apresentadas aos docentes em formação a possibilidade da troca de saberes e vivências, a oportunidade de impactar e influenciar mudanças na comunidade em que atuam, servindo para unir a pesquisa, a produção de saberes e as questões sociais (VIDAL; ALVES, 2020).

Logo, a participação dos acadêmicos dos cursos de licenciatura em projetos de extensão ajuda a construir os saberes docentes, permitindo atingir um entendimento mais 
amplo a respeito das diferentes condições em que se exerce a profissão docente e serve de base para sua prática profissional. E, consequentemente, durante a graduação, os acadêmicos que se envolvem em projetos de extensão dispõem de uma oportunidade a mais de inserção na realidade que encontrarão quando tornarem-se professores (CASTRO, 2009).

Nesse contexto, projetos de extensão como o Biotemas, da Universidade Estadual de Montes Claros, inserem os acadêmicos na realidade docente e permitem que eles reelaborem o pensamento do que é ser professor, buscando uma formação mais ampla até o término da graduação. Ao participar desse projeto, os graduandos planejam atividades metodológicas alternativas e dinâmicas, como a aplicação de oficinas pedagógicas, mas também vão conhecendo as relações professor-professor, professor-aluno e toda a condição social e afetiva que se constrói na escola.

Especificamente sobre o Biotemas, vale destacar que:

O Biotemas favorece a intervenção de futuros profissionais na prática social, promove também uma revisão da prática e teoria que os formam, tendo em vista a pesquisa e produção de novos conhecimentos para a teoria e a prática de ensinar. Proporciona a aproximação da instituição com a sociedade, a interação das atividades de ensino e pesquisa com as demandas da educação básica, enfim, promover ações para uma educação escolar de qualidade (FONSECA; OLIVEIRA, 2013, p. 14).

Dessa forma, pode-se destacar que os projetos e programas de extensão são especiais para o entendimento e compreensão plena de uma universidade. E o Programa Biotemas, tema desta pesquisa, é imensamente importante, uma vez que possibilita a integração de pessoas, vivências e experiências de novos profissionais, determinando, em certa medida, sua responsabilidade com o desenvolvimento educacional da região.

\section{O Programa Biotemas no ano de 2018: Articulação Universidade - Escola}

No ano de 2018, o Programa Biotemas atuou em parceria com escolas, a saber: Escola Estadual Antônio Canela, Escola Estadual Antônio Figueira e Escola Estadual Professor Hamilton Lopes, com a participação de diversos cursos da Unimontes e de outras instituições.

Sendo os cursos de Artes/Música, Ciências Biológicas - Licenciatura e Bacharel, Ciências da Religião, Ciências Sociais, Direito, Educação Física, Enfermagem, Engenharia de Sistemas, Filosofia, Geografia, História, Letras Inglês e Português, Matemática, Medicina, Música, Odontologia, Pedagogia, Serviço Social e dos Programas de Pós-Graduação de Ciências Biológicas da Universidade Estadual de Montes Claros. Já os cursos de Engenharia Florestal e Agronomia participantes foram da Universidade Federal de Minas Gerais (UFMG) e do Instituto Federal de Educação, Ciência e Tecnologia do Norte de Minas (IFNMG), junto com os cursos de Pedagogia, Engenharia Civil e Matemática do Instituto Superior de 
Educação Ibituruna (ISEIB) e Faculdades PROMINAS, e dos cursos de Medicina Veterinária, Enfermagem, Engenharia Elétrica e Engenharia Mecânica das Faculdades Unidas do Norte de Minas (FUNORTE).

As Instituições parceiras no ano de 2018 foram, então, as Faculdades de Saúde Ibituruna, Faculdades Unidas do Norte de Minas, Faculdades Integradas Pitágoras, Instituto Federal de Educação, Ciência e Tecnologia do Norte de Minas, Instituto Superior de Educação Ibituruna, Faculdades PROMINAS e Universidade Federal de Minas Gerais.

No ano de 2018, foram apresentadas 181 oficinas para os discentes do ensino fundamental, séries iniciais e finais, e do ensino médio das Escolas supracitadas - lembrando que uma mesma oficina poderia ser aplicada em diferentes turmas -, coordenadas por 257 professores - docentes do ensino básico e das instituições de ensino superior - com atividades apresentadas por 621 acadêmicos dos diversos cursos.

Teve a participação de 24 cursos de graduação e 01 de pós-graduação que ministraram oficinas no ensino médio e ensino fundamental I e II, nas escolas públicas que participaram do Biotemas no ano de 2018, sendo 16 cursos de graduação e 01 pós-graduação da Universidade Estadual de Montes Claros, 02 cursos de graduação da Universidade Federal de Minas Gerais, 03 do Instituto Superior de Educação Ibituruna - ISEIB / Faculdades PROMINAS e 03 da Faculdades Unidas do Norte de Minas - FUNORTE. Observa-se que os cursos que mais ministram oficinas foram o curso de Ciências Biológicas, com 23,73\%, seguido do curso de Matemática, com 20,90\% e Geografia com 6,78\%.

Sobre o número de oficinas ministradas por segmentos, o qual apresenta o quantitativo de oficinas por curso ministradas no ensino médio no Biotemas, no ano de 2018. Mais uma vez os cursos que se destacam são Ciências Biológicas, Matemática e Geografia. Dentre todos os cursos, foram apresentadas 74 oficinas, ministradas por 234 acadêmicos e 104 professorescoordenadores, aplicadas para os discentes do ensino médio das Escolas Estudais Antônio Canela e Professor Hamilton Lopes. Destaca-se que todas as atividades promovidas nessas escolas ocorreram no turno matutino, especificamente, das $7 \mathrm{~h}$ às 9 horas da manhã e de $10 \mathrm{~h}$ às 11 horas.

O número de oficinas por curso ministradas no ensino fundamental I no Biotemas, no ano de 2018. Divergindo das oficinas aplicadas no ensino médio, os cursos que se destacam são Pedagogia, seguidos de Matemática e Ciências Biológicas. Foram apresentadas 34 oficinas, ministradas por 138 acadêmicos e 49 professores-coordenadores, aplicadas para os discentes do ensino fundamental I da Escola Estadual Antônio Figueira no turno vespertino, especificamente das $13 \mathrm{~h}$ às 15 horas e das $16 \mathrm{~h}$ às $17 \mathrm{~h} 30 \mathrm{~min}$. 
Ressalta-se que o número de oficinas por curso ministradas no ensino fundamental II no Biotemas, no ano de 2018. Os cursos que se destacaram em números de oficinas apresentadas foram Ciências Biológicas, Matemática e Geografia. Foram apresentadas 73 oficinas, ministradas por 249 acadêmicos e com a participação de 104 professorescoordenadores, aplicando a dinâmica das oficinas para os discentes do ensino fundamental II das Escolas Estaduais Antônio Canela, Antônio Figueira e Professor Hamilton Lopes.

\section{O curso de Licenciatura em Geografia e sua imersão no Programa Biotemas - 2018}

A articulação entre teoria e prática é sempre um grande desafio na formação de professores. Entre planejar e executar algo há uma grande distância que, no entanto, pode ser superada. Um dos modos possíveis para a superação dessa situação é a construção de estratégias de integração entre pressupostos teóricos e práticos, o que, fundamentalmente, caracteriza as oficinas e minicursos pedagógicos, por exemplo.

Por meio das oficinas realizadas em projetos e programas de extensão universitária, como o Biotemas, é possível estabelecer aulas de Geografia com caráter educativo, atrativo e dinâmico. Sendo assim, os professores e os acadêmicos da graduação têm a oportunidade de inserir no ensino básico diversas estratégias e diferentes metodologias no sentido de estimular os alunos a aprender e a exercitar seu conhecimento crítico e analítico do espaço vivido e a influência do global de forma lúdica, atrativa, dinâmica e, sobretudo, significante para a vida daqueles.

O curso de Geografia - Licenciatura ministrou um total de 10 oficinas no ano de 2018, e essas foram aplicadas no ensino fundamental I e II e no ensino médio - relembra-se, nesse momento, que uma mesma oficina poderia ser aplicada em diferentes turmas e em distintos turnos. Participaram da aplicação dessas oficinas 49 acadêmicos e 16 professorescoordenadores do curso de Geografia.

QUADRO 01. Oficinas realizadas pelo curso de Geografia - Licenciatura no ano de 2018.

\begin{tabular}{|l|l|l|l|}
\hline OFICINA & PÚBLICO-ALVO & $\begin{array}{l}\text { PROFESSORES/ } \\
\text { COORDENADORES }\end{array}$ & ACADÊMICOS \\
\hline $\begin{array}{l}\text { A flexibilidade dos pontos } \\
\text { cardeais por meio das } \\
\text { brincadeiras e histórias infantis }\end{array}$ & $\begin{array}{l}7^{\circ} \text { e } 8^{\circ} \text { anos do ensino } \\
\text { fundamental }\end{array}$ & 01 & 06 \\
\hline $\begin{array}{l}\text { Caça ao tesouro: desvendando o } \\
\text { enigma dos mapas }\end{array}$ & $\begin{array}{l}6^{\circ} \text { e } 7^{\circ} \text { anos do ensino } \\
\text { fundamental }\end{array}$ & 01 & 05 \\
\hline Caraça: O que é isso? & $\begin{array}{l}1^{\circ} \text { ao } 3^{\circ} \text { ano do ensino } \\
\text { médio e 6 } 6^{\circ} \text { aos 9 anos } \\
\text { do ensino fundamental }\end{array}$ & 04 & 08 \\
\hline $\begin{array}{l}\text { Cartografia tátil: práticas e } \\
\text { métodos de inclusão social nas } \\
\text { abordagens com uso de mapas }\end{array}$ & $1^{\circ}$ ano do ensino médio & 01 & 04 \\
\hline
\end{tabular}




\begin{tabular}{|l|l|l|l|}
\hline no ensino médio & & \\
\hline $\begin{array}{l}\text { Criar: aula prática sobre o } \\
\text { processo de formações de } \\
\text { Vulcões. }\end{array}$ & $\begin{array}{l}6^{\circ} \text { ano do ensino } \\
\text { fundamental }\end{array}$ & 01 & 04 \\
\hline $\begin{array}{l}\text { Mão na massa: vamos construir } \\
\text { o relevo? }\end{array}$ & $\begin{array}{l}6^{\circ} \text { ao } 9^{\circ} \text { anos ensino } \\
\text { fundamental }\end{array}$ & 01 & 04 \\
\hline Mistérios dos solos & $\begin{array}{l}6^{\circ}, 7^{\circ} \text { e } 9^{\circ} \text { anos ensino } \\
\text { fundamental }\end{array}$ & 01 & 05 \\
\hline O que tem de útil no Cerrado & $\begin{array}{l}5^{\circ} \text { ano do ensino } \\
\text { fundamental }\end{array}$ & 02 & 06 \\
\hline $\begin{array}{l}\text { Orientando-se na Terra: a } \\
\text { Cartografia no cotidiano }\end{array}$ & $\begin{array}{l}6^{\circ} \text { e } 7^{\circ} \text { anos do ensino } \\
\text { fundamental }\end{array}$ & 01 & 04 \\
\hline $\begin{array}{l}\text { Revitalização ou Transposição } \\
\text { do rio São Francisco: como } \\
\text { funciona e os impactos da } \\
\text { escolha }\end{array}$ & $\begin{array}{l}1^{\circ} \text { ao } 3^{\circ} \text { anos do ensino } \\
\text { médio }\end{array}$ & 03 & 03 \\
\hline Total & $\mathbf{1 6}$ & $\mathbf{4 9}$ \\
\hline
\end{tabular}

Fonte: Arquivos documentais do Biotemas, 2019. Org: REIS, C. C. C. 2020.

Sobre as oficinas de Geografia ministradas no Biotemas 2018, destacam-se algumas de suas características, descritas a seguir.

\section{OFICINA: A flexibilidade dos Pontos Cardeais por meio das brincadeiras e histórias infantis}

A oficina teve como objetivo apresentar as contribuições das brincadeiras e histórias infantis no ensino e aprendizado dos discentes acerca dos conhecimentos de orientação, por meio das atividades lúdicas, com jogos e sua eficácia na construção do conhecimento geográfico dos discentes sobre os pontos cardeais e colaterais. A oficina foi ministrada na Escola Estadual Hamilton Lopes e na Escola Estadual Antônio Figueira para os alunos dos $7^{\circ}$ e $8^{\circ}$ anos do ensino fundamental. Utilizou-se a revisão bibliográfica por meio de livros didáticos.

\section{OFICINA: Caça ao tesouro: desvendando o enigma dos mapas}

A oficina foi ministrada para os discentes $\operatorname{dos} 6^{\circ}$ e $7^{\circ}$ anos do ensino fundamental II da Escola Estadual Professor Hamilton Lopes. A abordagem metodológica consistiu no uso de mapas, rosa dos ventos e bússola; primeiramente foi explicada a parte teórica. Objetivo desta oficina era que o aluno deveria descobrir em qual ponto cardeal se encontrava e de qual ponto colateral deveria iniciar, criando-se assim estratégias para encontrar o tesouro com a utilização dos recursos apresentados.

\section{OFICINA: Caraça: $O$ que é isso?}

O Caraça é uma Reserva Particular do Patrimônio Nacional - RPPN, simbolizado por um rosto humano esculpido pela própria natureza na Serra do Espinhaço, localizado entre os 
municípios de Santa Bárbara e Catas Altas, a 120 km da capital mineira Belo Horizonte. A oficina foi realizada nas Escolas Estaduais Antônio Canela, Antônio Figueira e Professor Hamilton Lopes. O objetivo desta oficina foi apresentar o Santuário do Caraça mostrando as belezas cênicas e naturais, sensibilizando para a preservação do meio ambiente. A metodologia utilizada iniciou-se com o uso de recursos midiáticos apresentando o que é o Caraça e dialogando sobre o tema. Após, foi exibido um documentário sobre esse, seguido de discussão de roteiro para acompanhar a exibição. Na etapa final, foi entregue uma folha em branco para os discentes expressarem por meio de desenhos o que mais chamou a atenção no minicurso, ou criar um slogan sobre o Caraça.

OFICINA: Cartografia tátil: Práticas e métodos de inclusão social nas abordagens com uso de mapas no ensino médio

O objetivo da oficina foi mediar junto aos alunos do ensino médio e produzir um mapa para deficientes visuais. Sendo assim, os portadores de tal limitação, utilizam o método Braille para ler e escrever, mas precisam também de adaptações para que consigam ter um bom aprendizado dentro da sala de aula, como para fazer leitura e análises de mapas, gráficos, recursos iconográficos. Os alunos contemplados com a oficina foram do $1^{\circ}$ ano do ensino médio da Escola Estadual Hamilton Lopes, aos quais foi solicitado que mantivessem os olhos fechados e se colocassem na posição de um deficiente visual, lendo a legenda e o mapa por meio do tato.

\section{OFICINA: Criar: Aula prática sobre o processo de formação de vulcões}

Foi realizada a oficina na Escola Estadual Antônio Figueira, no $6^{\circ}$ ano. Foram abordados os seguintes tópicos: principais falhas geológicas; as placas tectônicas; processo evolutivo e formação dos vulcões. Abordando esses conteúdos, o objetivo da oficina foi promover um espaço de diálogos intervindo com aula prática no processo de ensinoaprendizagem acerca do processo de formação de vulcões.

\section{OFICINA: Mão na massa: Vamos construir o relevo?}

A oficina foi realizada pelos acadêmicos do $4^{\mathrm{o}}$ período do curso de Geografia, desenvolvida na Escola Estadual Antônio Figueira, para alunos do ensino fundamental II, o objetivo desta foi trabalhar a capacidade de representação do relevo pelos discentes e discutir como esse influência no cotidiano dos alunos. Foram basilares teóricos clássicos que discutem o tema e a reflexão sobre as categorias Paisagem e Território. Posteriormente, foi distribuída 
argila para os alunos, o suficiente para o manuseio e construção do relevo. Iniciou-se um processo de construção, em que os alunos puderam individualmente modelar as formas de relevo de acordo com as explicações expostas pelos acadêmicos, bem como analisar todas as variações de altitude e nomeá-los.

\section{OFICINA: Mistérios dos solos}

O minicurso Mistérios do Solo foi ministrado para os alunos do ensino fundamental dos $6^{\circ} 7^{\circ}$ e $9^{\circ}$ anos da Escola Estadual Professor Hamilton Lopes. O conteúdo foi repassado aos alunos por meio de aula expositiva e dialogada, com recursos multimídia (notebook) de áudio (caixa de som) e vídeo (projetor), jogos e quiz educativos, feitos manualmente pelos acadêmicos, e experiências com recursos naturais.

\section{OFICINA: $O$ que tem de útil no Cerrado?}

A oficina foi aplicada para discentes do $5^{\circ}$ ano do ensino fundamental na escola Estadual Antônio Figueira, cujo objetivo foi destacar as características físicas do Bioma Cerrado, como os solos, hidrologia e a cultura dos povos tradicionais que vivem no Cerrado brasileiro.

\section{OFICINA: Orientando-se na terra: A cartografia no cotidiano}

A oficina foi realizada na Escola Estadual Antônio Canela; foram utilizados alguns procedimentos, em que primeiramente realizou-se revisão bibliográfica referente à ciência Cartográfica e ao ensino dessa. Em seguida, foram confeccionados dois globos terrestres em que se tinha a representação dos paralelos e meridianos em um e o segundo globo representando os continentes, com a finalidade de tornar o ensino e aprendizado mais atrativos para os alunos. Para elaboração dos globos foram utilizados bolas de isopor de 80 centímetros de diâmetro, isopor de $1 \mathrm{~m}^{2}$, E.V.A. azul e preto, cola quente, caneta para retroprojetor, livro didático e Atlas como suporte teórico.

\section{OFICINA: Revitalização ou Transposição do Rio São Francisco como funciona e os impactos da escolha}

O objetivo da oficina foi apresentar aos alunos do ensino médio a degradação antrópica ambiental do rio São Francisco, principalmente da fauna e flora, os impactos causados pela transposição do rio para as comunidades ribeirinhas tracionais e como isso afeta 
a dinâmica dos conflitos territoriais. Foi iniciada uma discussão com os discentes sobre o assunto abordado durante a oficina.

Foram desenvolvidas 10 oficinas por professores e acadêmicos do curso de Licenciatura em Geografia com as seguintes temáticas: Cartografia; Geologia; Geomorfologia; Degradação Ambiental; Pedologia; sendo destaque a Cartografia, Geomorfologia e Geologia entre os temas. Pode-se observar que a maioria dos temas abordados nas oficinas ministradas pelo curso de Geografia - Licenciatura, foram voltados para o ensino de Geografia Física e Cartografia. Temas que muitos acadêmicos de Geografia e discentes da educação básica destacam uma dificuldade eminente no processo de mediá-los e problematizá-los.

Segundo Girardi (2001), as dificuldades dos geógrafos em trabalhar, entender e lidar com mapas acabam acarretando distorções no seu uso tanto como etapa metodológica, no ensino, como meio de comunicação de resultado de pesquisa. Menciona o autor, também, a urgência em refletir o papel do mapa na construção do raciocínio espacial e assim poder repensar o conteúdo das disciplinas de Cartografia nos cursos de Licenciatura em Geografia, cujas demandas, atualmente, vão de alfabetização cartográfica às geotecnologias.

Não é fundamental que o aluno saiba ler um mapa apenas para localizar geograficamente um rio, uma cidade, ou para saber que a Cordilheira dos Andes se situa na porção oeste da América do Sul. É preciso que ele saiba tecer interpretações e análises sobre o mapa (PORTO, 2001).

Diante das observações dos autores supramencionados, por meio da realização de oficinas no Biotemas (ano 2018), a exemplo das oficinas Criar: aula prática sobre o processo de formações de Vulcões; Orientando-se na Terra: A Cartografia no cotidiano; Caça ao Tesouro! Desvende o enigma dos mapas; A flexibilidade dos pontos cardeais por meio das brincadeiras e histórias infantis e Cartografia Tátil, ao apresentar aos discentes de maneira lúdica e descontraída auxilia para chamar a atenção e despertar a curiosidade dos discentes e praticar também o trabalho em equipe, além de trazer a Cartografia para a realidade do discente.

A metodologia das oficinas pedagógicas pode ser compreendida como uma prática de construção coletiva do conhecimento, em que as atividades realizadas são dinâmicas e exigem a interação e relação entre os participantes, seja professor, acadêmicos ou aluno. A finalidade dessas oficinas não é apenas desenvolver o saber por saber, mas levar em consideração toda a metodologia aplicada e desenvolvida e, assim, deve levar aos alunos a capacidade de articular 
e sintetizar a construção do conhecimento, contribuir no sentido de articular os conteúdos teóricos e práticos, deixando as aulas propositivas.

Nesse contexto, segundo Candau (1995), as oficinas se desenvolvem no lugar em que a construção do conhecimento se correlaciona com a realidade inserida, criando nesse processo um confronto entre teoria e experiências. E as oficinas como as realizadas no Biotemas conduzem os acadêmicos de licenciatura a serem agentes das suas técnicas de ensino por meio da aplicação e dos resultados obtidos nas práticas aplicadas nas ações do programa.

Ou seja, a realização das oficinas no Biotemas traz ao acadêmico que participa do programa prática docente, mecanismos para correlação entre a teoria e a prática, trazendo o conteúdo ministrado pelo docente a realidade do aluno, de forma simples, lúdicas e pedagógica.

\section{Considerações finais}

A presente pesquisa analisou a participação do curso de Geografia - Licenciatura no $15^{\circ}$ Fórum Biotemas no ano de 2018, Programa de extensão realizado pela Universidade Estadual de Montes Claros. Para isso, este estudo discorreu, em princípio, sobre a importância da indissociação do ensino, pesquisa e extensão na formação docente e ressaltou a importância da extensão para a formação acadêmica/profissional dos estudantes universitários.

Destacou os principais programas de extensão da Universidade Estadual de Montes Claros, como o Programa de Educação Tutorial (PET), Programa Institucional de Bolsa de Iniciação à Docência (PIBID), Programa Residência Pedagógica (RP), Projeto Núcleo de Atividades para Promoção da Cidadania (NAP) e Projeto Unimontes Solidária e, em destaque, o Programa Biotemas.

No ano de 2018 foram apresentadas 181 oficinas para os discentes das Escolas Estaduais Antônio Canela, Antônio Figueira e Professor Hamilton Lopes, coordenadas por 257 professores-coordenadores e apresentadas por 621 acadêmicos dos diversos cursos participantes no ensino fundamental I/II e ensino médio. O curso de Geografia - Licenciatura ministrou um total de 10 oficinas que foram aplicadas no ensino fundamental I, II e no ensino médio. Participaram da aplicação dessas oficinas 49 acadêmicos e 16 professorescoordenadores do curso de Geografia.

No que se refere aos resultados obtidos nos trabalhos desenvolvidos pelos acadêmicos e professores do curso de Geografia com os estudantes da educação básica, pode-se inferir 
que a participação é expressiva, pois é o terceiro curso que mais apresentou oficinas no Biotemas no ano de 2018.

As oficinas, como as realizadas pelo curso de Geografia no Biotemas, conduzem os acadêmicos de licenciatura a serem agentes das suas técnicas de ensino por meio da aplicação e dos resultados obtidos nas práticas aplicadas nas ações do programa.

\section{Referências}

ALTET, M. As competências do professor profissional: entre conhecimentos, esquemas de ação e adaptação, saber analisar. In: PERRENOUD, F.; PAQUAY, L.; ALTET, M.; CHARLIER, E (Orgs.). Formando professores profissionais: quais estratégias? Quais competências? Porto Alegre: Artmed, 2001. pp. 23-35.

ANDES. Associação Nacional dos Docentes de Ensino Superior. Proposta do ANDES-SN para a Universidade Brasileira, $\mathrm{n}^{\circ}$ 2, $3^{\mathrm{a}}$ ed. Brasília/DF, 2003.

BIOTEMAS UNIMONTES. Programa Biotemas. Página inicial. Disponível em: <https://biotemasunimontes.com/>. Acesso em: Acesso em: 8 de set. 2020.

BRASIL. [Constituição (1988)1988)]. Constituição da República Federativa do Brasil de 1988. Brasília, DF: Presidência da República, 2016.

BRASIL. Lei no 9.394, de 20 de dezembro de 1996. Lei de Diretrizes e Bases da Educação Nacional. Diário Oficial da União, Brasília, 24 dez. 1996.

BRASIL. Ministério da Educação. Secretaria de Educação Superior. Fórum de PróReitores de Extensão das Universidades Públicas Brasileiras. Universidade Federal de Minas Gerais - PROEX, 2017.

CANDAU, V. M. et al. Oficinas pedagógicas de direitos humanos. $2^{\text {a }}$ ed. Petrópolis, RJ: Vozes, 1995.

CASTRO, C. M. Desventuras do ensino médio e seus desencontros com o profissionalizante. In: VELOSO, F.; PESSÔA, S.; HENRIQUES, R.; GIAMBIAGI, F. (Orgs.). Educação básica no Brasil: construindo o país do futuro. Rio de Janeiro: Elsevier, 2009. pp. 145-169.

CAVALCANTE, J. Evolução do ensino Superior-graduação - 1980/1998. Brasília: Instituto Nacional de Estudos e Pesquisas Educacionais, 2000.

CASTELLAR, S. J. V. Ensino de geografia. São Paulo: Cengage Learning, 2011.

ESTEVE, J. M. Mudanças sociais e função docente. Portugal: Porto Editora, 1995.

FERNANDES, M. C.; SILVA, L. M. S.; MACHADO, A. L. G.; MOREIRA, T. M. M. Universidade e a extensão universitária: a visão dos moradores das comunidades circunvizinhas. In.: Educação em Revista, v. 28, n 4., pp. 169-193.

FONSECA, G. S; OLIVEIRA, I. C. Contribuições do curso de Geografia no Fórum de Biotemas na Educação Básica. In.: Intercâmbio, Montes Claros, v. 4, n. 1, pp. 80-91, 2013. 
FREIRE, Paulo. Extensão ou Comunicação. $7^{a}$ edição. Rio de Janeiro. Paz e Terra. 1983.

GARCIA, B. R. Z. Garcia, Berenice Rocha Zabbot. The contribution of the university extension for teacher's education. $115 \mathrm{f}$. Tese (Doutorado em Psicologia) - Pontifícia Universidade Católica de São Paulo, São Paulo, 2012.

GIRARDI, G. A Cartografia no Ensino Superior de Geografia: Desafios e Possibilidades. In.: Boletim de Geografia, Universidade Estadual de Maringá, ano 19, nº 2, pp. 29, 2001.

IMBERNÓN, F. Formação docente e profissional: formar-se para a mudança e a incerteza. $5^{\mathrm{a}}$ ed. São Paulo: Cortez, 2005.

LOPES, E. P.; COSTA, W. N. G. Contribuições da extensão universitária à formação docente. In.: [Anais...] Encontro Nacional de Educação Matemática, São Paulo- SP, 2016.

LEITE, M. E; PEREIRA, M A. M. Expansão territorial e os espaços de pobreza na cidade de montes claros. In.: [Anais...] do X Encontro de Geógrafos da América Latina, Universidade de São Paulo, 2005

MARIN, I. S. K. Sujeito - desamparo e violência. In.: [Anais...] III Congresso de Psicopatologia Fundamental. Painel: Violência, dor, desamparo. São Paulo, abril de 1998.

MOITA, F. M. G. S.; DE ANDRADE, F. C. B. Ensino-pesquisa-extensão: um exercício de indissociabilidade na pós-graduação. In.: Revista brasileira de educação, v.14, n.41, pp. 269-393, 2002.

NAP UNIMONTES. Projeto do Núcleo de Atividades para Promoção da Cidadania. Página inicial. Disponível em: <http://www.nap.unimontes.br/index.php/projeto-nap.html>. Acesso em: Acesso em: 8 de set. 2020.

PAULA, João Antônio de. A extensão universitária: história, conceito e propostas. In.: Revista Extensão da UFMG; v. 1, n. 1, p. 05-23, jul. /nov. 2013.

PENIN, S. T. S. Profissão docente. Salto para o futuro. In.: Revista Educação Crítica, Rio de Janeiro, v. 19, n. 14, out. 2009a.

PONTUSCHKA, N.N.; PAGANELli, T; CACETE, N. H. Para ensinar e aprender Geografia. $3^{\text {a }}$ ed. Editora Cortez. São Paulo, 2009.

PORTAL MEC. Ministério da Educação. Página inicial. Disponível em: < http://portal.mec.gov.br/>. Acesso em: Acesso em: 8 de set. 2020.

PORTO, A.P. O Mapa Como Recurso Didático: Uma Reflexão Sobre seu Papel de Instrumento Para o Ensino de uma Geografia Crítica e Análise de seu Objeto de Estudo. In.: Boletim de Geografia, Universidade Estadual de Maringá, ano 19, nº 2, 2001.

RAYS, O. A. Ensino-Pesquisa-Extensão: notas para pensar a indissociabilidade. In.: Revista Cadernos de Educação Especial, n. 21, 2003, pp. 71- 85.

SANTOS, B. S. A universidade no século XXI: para uma reforma democrática e emancipatória da universidade. São Paulo: Cortez, 2010. 
SANTOS, L. L. C. P. Dilemas e perspectivas na relação entre ensino e pesquisa. In: ANDRÉ, Marli (Org.). O papel da pesquisa na formação e na prática dos professores. Campinas: Papirus, 2001. pp. 11-26.

SAVIANI, D. Escola e democracia. São Paulo: Cortez, Autores Associados, 1985. Tendências e correntes da educação no Brasil. In: MENDES, D. T. (Coord.). Filosofia da educação brasileira. $3^{a}$ edição. Rio de Janeiro-RJ: Civilização Brasileira, 1987. pp.19-47.

SAVIANI, D. Formação de professores: aspectos históricos e teóricos do problema no contexto brasileiro. In.: Revista Brasileira de Educação, Rio de Janeiro, v. 14, n. 40, pp. 143-155, abr. 2009.

SEVERINO, A. J. Metodologia do Trabalho Científico. São Paulo: Cortez, 2017.

SILVA, M. A.; FONSECA, S. G. Ensino de História hoje: errâncias, conquistas e perdas. In.: Revista Brasileira de História, v. 30, p. 13-33, 2010.

SILVA, M. F. da. MENDOZA, C. C. G. A importância do ensino, pesquisa e extensão na formação do aluno do Ensino Superior. In.: Revista Científica Multidisciplinar Núcleo do Conhecimento. Ano 05, Ed. 06, Vol. 08, pp. 119-133. Junho de 2020.

VIDAL, V. C. C.; ALVES, R de C. Programas e Projeto de extensão da Universidade Estadual de Montes Claros (Unimontes): contribuições do PIBID, RP e NAP na formação inicial docente. In.: Revista Intercâmbio - vol. XVII, pp. 001-17, 2020.

Artigo recebido em: 11/01/2021. Artigo aceito em: 23/02/2021. 